\title{
Combined thiazolidinedione-metformin treatment synergistically improves insulin signalling to insulin receptor substrate-1-dependent phosphatidylinositol 3-kinase, atypical protein kinase $C$ and protein kinase B/Akt in human diabetic muscle
}

\author{
N. Temofonte $\cdot$ M. P. Sajan • S. Nimal • T. Pastoor • \\ C. Fumero • L. Casaubon • J. L. Powe • \\ M. L. Standaert • R. V. Farese
}

Received: 9 September 2008 /Accepted: 30 September 2008 / Published online: 30 October 2008

(C) Springer-Verlag 2008

\begin{abstract}
Aims/hypotheses Insulin-stimulated glucose transport in muscle is impaired in type 2 diabetes, presumably reflecting reduced activation of atypical protein kinase $\mathrm{C}(\mathrm{aPKC})$ and protein kinase $\mathrm{B}$ ( $\mathrm{PKB} / \mathrm{Akt})$. As previously shown, reductions in aPKC activation are seen at sub-maximal and maximal insulin stimulation, reductions in PKB activation are best seen at sub-maximal insulin stimulation and aPKC reductions at maximal insulin are partly improved by thiazolidinedione or metformin treatment. However, effects of combined thiazolidinedione-metformin treatment on aPKC or PKB activation by sub-maximal and maximal insulin are unknown.
\end{abstract}

N. Temofonte $\cdot$ M. P. Sajan · C. Fumero $\cdot$ L. Casaubon •

J. L. Powe $\cdot$ M. L. Standaert $\cdot$ R. V. Farese $(\square)$

Research Service, James A. Haley Veterans Administration

Medical Center,

13000 Bruce B. Downs Blvd.,

Tampa, FL 33612, USA

e-mail: rfarese@health.usf.edu

N. Temofonte $\cdot$ M. P. Sajan $\cdot$ C. Fumero $\cdot$ L. Casaubon $\cdot$

J. L. Powe $\cdot$ M. L. Standaert $\cdot$ R. V. Farese

Department of Internal Medicine,

University of South Florida College of Medicine,

Tampa, FL, USA

S. Nimal $\cdot$ T. Pastoor $\cdot$ R. V. Farese

Roskamp Institute,

Sarasota, FL, USA
Methods Type 2 diabetic patients were examined before and 5 to 6 weeks after combined thiazolidinedionemetformin therapy for activation of muscle aPKC and $\mathrm{PKB} \beta$ and their upstream activators, the insulin receptor (IR) and IRS-1-associated phosphatidylinositol 3-kinase (PI3K), during euglycaemic-hyperinsulinaemic clamp studies conducted with sub-maximal (400-500 pmol/1) and maximal (1400 pmol/1) insulin concentrations.

Results Following combined thiazolidinedione-metformin therapy, increases in glucose disposal and increases in submaximal and maximal insulin-induced activities of all four muscle signalling factors, IR, IRS-1-dependent PI3K (IRS$1 / \mathrm{PI} 3 \mathrm{~K}), \mathrm{aPKC}$ and $\mathrm{PKB} \beta$, were observed. Increases in PKB $\beta$ enzyme activity were accompanied by increases in phosphorylation of PKB and its substrate, AS160, which is needed for glucose transport. Despite improved aPKC activity, muscle aPKC levels, which are diminished in type 2 diabetes, were not altered.

Conclusions/interpretation Combined thiazolidinedionemetformin treatment markedly improves sub-maximal and maximal insulin signalling to IR, IRS-1/PI3K, aPKC and $\mathrm{PKB} \beta$ in type 2 diabetic muscle. These improvements exceed those previously reported after treatment with either agent alone.

Keywords Atypical protein kinase C - Diabetes - Insulin . Insulin resistance $\cdot$ Muscle $\cdot$ Protein kinase B .

Protein kinase $\mathrm{C}-\zeta$ 


\begin{tabular}{ll}
\multicolumn{2}{l}{ Abbreviations } \\
aPKC & atypical protein kinase C \\
IR & insulin receptor \\
IRS-1/PI3K & IRS-1-dependent PI3K \\
PI3K & phosphatidylinositol 3-kinase \\
PKB/Akt & protein kinase B \\
PMSF & phenylmethylsulfonylfluoride
\end{tabular}

\section{Introduction}

Skeletal muscle insulin resistance in type 2 diabetes reflects diminished ability to increase glucose transport, which requires activation of the insulin receptor (IR) and IRS-1associated phosphatidylinositol 3-kinase (PI3K), followed by activation of atypical protein kinase $\mathrm{C}$ (aPKC) and protein kinase $\mathrm{B}$ (PKB/Akt), and translocation of GLUT4 glucose transporters to the plasma membrane.

In type 2 diabetic muscle, reductions in IRS-1-dependent PI3K (IRS-1/PI3K) [1] and aPKC activation [2-4] were seen in studies employing sub-maximal and/or maximal insulin stimulation. However, PKB activation was not reduced in some studies of maximal insulin stimulation $[2,5]$, but reduced PKB activation was evident with submaximal (more physiological) insulin stimulation [4, 6-8].

Knowledge of effectiveness of insulin-sensitising agents on signalling factors in diabetic muscle is limited. Thiazolidinediones increased IRS-1/PI3K [2, 9] and aPKC activation [2], and metformin increased aPKC activation [10] in studies utilising maximal insulin stimulation. However, studies at sub-maximal insulin are lacking. Furthermore, in studies where $\mathrm{PKB} / \mathrm{Akt}$ activation at maximal insulin was not diminished, improvements with thiazolidinedione [2,9] or metformin [10] treatment may not have been evident; these studies, moreover, did not examine PKB $\beta$ or its substrate, AS160, which are more relevant to glucose transport. Finally, combined thiazolidinedione-metformin therapy is a clinically useful treatment for type 2 diabetes, but effects on insulin signalling are unknown.

Here, we examined, before and at 5 to 6 weeks after thiazolidinedione-metformin therapy, activation of muscle IR, IRS-1/PI3K, aPKC and PKB during euglycaemichyperinsulinaemic clamps; we observed impressive improvements in these signalling factors at both submaximal and maximal insulin stimulation.

\section{Methods}

We studied five type 2 diabetic patients (four men, one woman; results of aPKC and PKB activation in men and women are indistinguishable $[2,4,10])$, who were free of cardiovascular, renal, neuropathic and other medical problems. Procedures were approved by the Institutional Review Board of the University of South Florida College of Medicine and the Research and Development Committee of the James A. Haley Veterans Hospital, and were in accordance with the Declaration of Helsinki and Good Clinical Practice.

After obtaining informed consent, diabetic medications (sulfonylurea and/or metformin) were discontinued for 3 to 4 weeks before the pre-treatment clamp/biopsy study, conducted first at sub-maximal, and 1 to 2 weeks later at maximal insulin stimulation. Identical studies were conducted 5 to 6 weeks after daily treatment with $8 \mathrm{mg}$ rosiglitazone and $2000 \mathrm{mg}$ metformin. Clamp/biopsy procedures were also conducted in non-diabetic non-obese men to provide control samples for side-by-side analyses with diabetic samples (this study of effects of combined thiazolidinedione-metformin therapy was terminated with reports of cardiovascular problems associated with usage of rosiglitazone).

Euglycaemic-hyperinsulinaemic clamp/muscle biopsy studies were conducted after overnight fasting, as described $[2,4,10]$. After anaesthetising with $0.5 \%$ lidocaine, the skin was incised and a biopsy of the vastus lateralis muscle was performed with a 14-gauge needle. Insulin was then given intravenously in a priming dose (14 or $42 \mathrm{pmol}[\mathrm{kg}$ body weight $]^{-1} \min ^{-1}$, for sub-maximal or maximal insulin treatments, respectively) over $10 \mathrm{~min}$ and then at a constant rate proportional to body weight to attain serum insulin concentrations of approximately 400 to $500 \mathrm{pmol} / 1$ or $1,400 \mathrm{pmol} / 1$ insulin, which elicit approximately halfmaximal and maximal effects on glucose disposal [4]. Plasma glucose was clamped at 5 to $6.1 \mathrm{mmol} / \mathrm{l}$ by administration of $20 \%$ glucose. The clamp was continued for 90 to $120 \mathrm{~min}$ to attain steady-state glucose levels, whereupon a second biopsy was obtained. Glucose disposal rates were determined during the last $30 \mathrm{~min}$. Muscle samples were flash-frozen (liquid $\mathrm{N}_{2}$ ) and stored at $-70^{\circ} \mathrm{C}$.

Analytical methods for muscles, blood and serum have been described $[2,4,10]$. Briefly, muscle samples were homogenised in buffer containing $20 \mathrm{mmol} / \mathrm{l}$ Tris/ $\mathrm{HCl}$ (pH 7.5), $50 \mathrm{mmol} / 1$ sucrose, $2 \mathrm{mmol} / \mathrm{l} \mathrm{EDTA}, 2 \mathrm{~mol} / \mathrm{l} \mathrm{EGTA}$, $2 \mathrm{mmol} / 1 \mathrm{Na}_{3} \mathrm{VO}_{4}, 2 \mathrm{mmol} / \mathrm{l} \mathrm{NaF}, 2 \mathrm{mmol} / 1 \mathrm{Na}_{4} \mathrm{P}_{2} \mathrm{O}_{7}$, $1 \mathrm{mmol} / \mathrm{l}$ phenylmethylsulfonylfluoride (PMSF), $20 \mu \mathrm{g} / \mathrm{ml}$ leupeptin, $10 \mu \mathrm{g} / \mathrm{ml}$ aprotinin, $1 \mu \mathrm{mol} / 1 \mathrm{LR}$-microcytstin, $150 \mathrm{mmol} / \mathrm{l} \mathrm{NaCl}, 1 \%$ Triton X-100 (vol./vol.) and 0.5\% Nonidet (vol./vol.).

To measure aPKC activation, aPKCs $(\zeta / \iota)$ were immunoprecipitated with a rabbit polyclonal antiserum (Santa Cruz Biotechnology, Santa Cruz, CA, USA), collected on Sepharose-AG beads and incubated for $8 \mathrm{~min}$ at $30^{\circ} \mathrm{C}$ in $100 \mu \mathrm{l}$ buffer containing: $50 \mathrm{mmol} / \mathrm{l} \mathrm{Tris} / \mathrm{HCl}(\mathrm{pH} 7.5), 100 \mu \mathrm{mol} / \mathrm{l}$ 
$\mathrm{Na}_{3} \mathrm{VO}_{4}, 100 \mu \mathrm{mol} / 1 \mathrm{Na}_{4} \mathrm{P}_{2} \mathrm{O}_{7}, 1 \mathrm{mmol} / 1 \mathrm{NaF}, 100 \mu \mathrm{mol} / 1$ PMSF, $4 \mu \mathrm{g}$ phosphatidylserine (Sigma, St Louis, MO, USA), $50 \mu \mathrm{mol} / 1\left[\gamma_{-}{ }^{32} \mathrm{P}\right] \mathrm{ATP}$ (NEN/Life Science Products, Boston, MA, USA), $5 \mathrm{mmol} / 1 \mathrm{MgCl}_{2}$ and $40 \mu \mathrm{mol} / \mathrm{l}$ serine analogue of the PKC- $\varepsilon$ pseudosubstrate (BioSource, Camarillo, CA, USA). After incubation, ${ }^{32} \mathrm{P}$-labelled substrate was trapped on P-81 paper and counted.

PKB activation was assessed by western blot analysis of phosphorylation of serine(Ser)-473 residues in total PKB and by $\mathrm{PKB} \beta$ enzyme activity, which was immunoprecipitated with rabbit polyclonal antiserum (Upstate Cell Signaling Technology, Lake Placid, NY, USA) or mouse monoclonal antibody (Santa Cruz Biotechnology) and assayed (reagents, Upstate Cell Signaling Technology).

IRS-1-associated PI3K activity was measured by immunoprecipitation of IRS-1 with rabbit polyclonal antiserum (Upstate Cell Signaling Technology) and essayed with PI, $\mathrm{MgCl}_{2}$ and $\left[\gamma-{ }^{32} \mathrm{P}\right] \mathrm{ATP}$. The reaction product, ${ }^{32} \mathrm{P}$-labelled $\mathrm{PI} 3-\mathrm{PO}_{4}$, was isolated by thin layer chromatography and quantified with a BioRad PhosphoImager (BioRad Laboratories, Hercules, CA, USA).

IR activation was assessed by immunoprecipitation of the $\beta$-subunit (rabbit polyclonal antiserum; Santa Cruz Biotechnology) followed by western blot analysis for phosphotyrosine content (mouse monoclonal antibodies; Santa Cruz Biotechnology).

Lysates were immunoblotted for PKC- $/ / \iota$ (C-terminal rabbit polyclonal antiserum; Santa Cruz Biotechnology), phospho-Ser-473-PKB (rabbit polyclonal antiserum; Upstate Cell Signaling Technology), phospho-AS160 (rabbit polyclonal antiserum; Upstate Cell Signaling Technology), IRS-1 (rabbit polyclonal antiserum; Santa Cruz Biotechnologies), p85 subunit of PI3K (rabbit polyclonal antiserum; Upstate Cell Signaling Technology) and PKB $\beta$ (rabbit polyclonal antibody; Upstate Cell Signaling Technology).

Statistical differences between two and more groups were evaluated by Student's $t$ test and one-way ANOVA with the least-significant multiple comparison method, respectively.

\section{Results}

Clinical characteristics are summarised in Table 1. Following thiazolidinedione-metformin treatment, fasting serum insulin levels decreased $(p<0.05)$ in type 2 diabetic patients, and levels of $\mathrm{HbA}_{1 \mathrm{c}}$ and fasting serum glucose, C-peptide, triacylglycerol, total cholesterol and LDL-cholesterol showed a downward trend.

In diabetic patients, whole-body glucose disposal (Fig. 1a) and muscle IR- $\beta$-subunit phosphotyrosine content (Fig. 1b) following sub-maximal and maximal insulin stimulation were markedly reduced before thiazolidinedione-metformin treatment, but increased after treatment, albeit not fully to normal.

Similarly, muscle IRS-1/PI3K (Fig. 1c) and aPKC (Fig. 1d) responded poorly to sub-maximal and maximal insulin stimulation before thiazolidinedione-metformin treatment, but improved markedly after treatment. $\mathrm{PKB} \beta / \mathrm{Akt} 2$ activation was markedly impaired with sub-maximal, and to a lesser degree with maximal insulin stimulation, but in both cases increased after thiazolidinedione--metformin treatment, (Fig. 1e). Moreover, phosphorylation of PKB (Fig. 1f) and its substrate, AS160 (Fig. 1g; required for GLUT4 glucose transporter translocation), was significantly enhanced with maximal insulin and revealed an upward trend at submaximal insulin stimulation. Levels of IR- $\beta$-subunit, IRS-1, p85/PI3K, p110/PI3K, total-PKB, PKB $\beta$, total-AS160 and total-aPKC were unaltered by treatment (Fig. 1h).

\section{Discussion}

Combined thiazolidinedione-metformin treatment was remarkably effective in improving submaximal and maximal
Table 1 Clinical characteristics of diabetic patients before and after combined thiazolidinedione-metformin treatment

Values are mean \pm SEM ${ }^{*} p<0.05$, post-treatment vs pre-treatment in diabetic participants; $\uparrow p<0.05$, non-diabetic control participants vs pretreated diabetic participants

\begin{tabular}{|c|c|c|c|}
\hline \multirow[t]{2}{*}{ Characteristic } & \multirow{2}{*}{$\frac{\text { Diabetic }}{\text { Pre-treatment }(n=5)}$} & \multicolumn{2}{|l|}{ Non-diabetic } \\
\hline & & Post-treatment $(n=5)$ & No-treatment $(n=4)$ \\
\hline Age (years) & $51 \pm 3$ & $51 \pm 3$ & $48 \pm 3$ \\
\hline BMI $\left(\mathrm{kg} / \mathrm{m}^{2}\right)$ & $35 \pm 3$ & $35 \pm 2$ & $26 \pm 1 \dagger$ \\
\hline Serum glucose (mmol) & $11.9 \pm 2.1$ & $7.6 \pm 1.1$ & $5.2 \pm 0.6 \dagger$ \\
\hline $\mathrm{HbA}_{1 \mathrm{c}}(\%)$ & $7.7 \pm 0.7$ & $7.1 \pm 0.9$ & $5.8 \pm 0.1 \dagger$ \\
\hline Serum insulin $(\mathrm{pmol} / \mathrm{l})$ & $159 \pm 28$ & $69 \pm 14^{*}$ & $63 \pm 21 \dagger$ \\
\hline Serum C-peptide (nmol/1) & $2.13 \pm 0.80$ & $1.23 \pm 0.23$ & $0.73 \pm 0.20$ \\
\hline Serum triacylglycerol (mmol) & $3.96 \pm 2.54$ & $2.43 \pm 1.36$ & $1.33 \pm 0.14$ \\
\hline Serum cholesterol $(\mathrm{mmol} / \mathrm{l})$ & $5.54 \pm 0.65$ & $4.79 \pm 1.78$ & $4.95 \pm 0.49$ \\
\hline LDL-cholesterol (mmol/l) & $2.80 \pm 0.36$ & $2.46 \pm 0.26$ & $2.72 \pm 0.23$ \\
\hline HDL-cholesterol (mmol/l) & $1.27 \pm 0.10$ & $1.09 \pm 0.16$ & $1.37 \pm 0.16$ \\
\hline
\end{tabular}


$a_{-}$

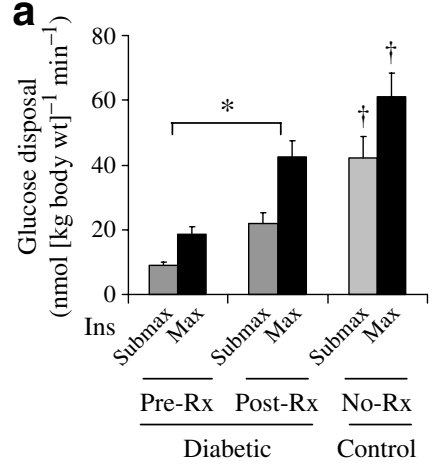

e

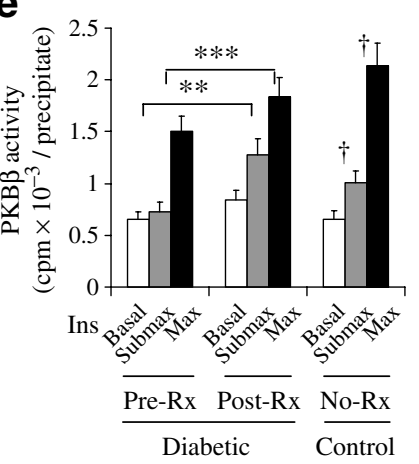

b

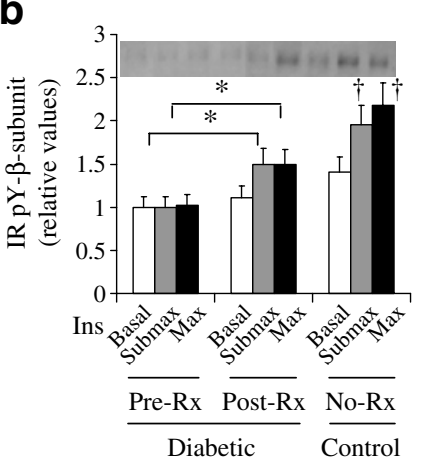

f

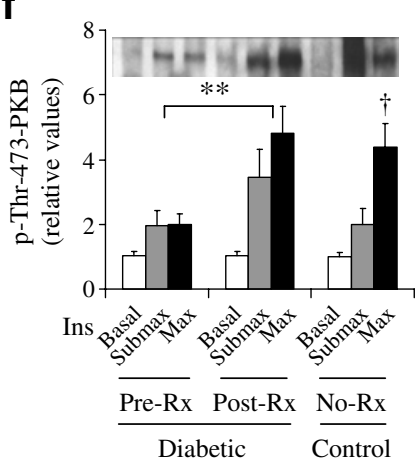

Fig. 1 Effects of combined thiaziolidinedione-metformin treatment (Rx) on sub-maximal (Submax) and maximally (Max) effective insulin (Ins) on whole-body glucose disposal rates (a), phosphotyrosine content (reflective of activation) of the IR $\beta$-subunit (b), IRS-1/ PI3K activity (c), atypical PKC- $\zeta / \iota$ activity (d), PKB $\beta /$ Akt 2 activity (e), phosphorylation of threonine-473 in total PKB (f) and phosphorylation of the PKB/Akt substrate AS160 (g) in muscles of type 2 diabetic participants. Basal, non-insulin-stimulated in clamp values. Also shown in each panel are basal and insulin-treated values of nondiabetic controls (Control) assayed in parallel with samples of diabetic participants. Values are mean $\pm \mathrm{SE}$ of five determinations for diabetic participants and four to five determinations for controls. ANOVA for effects of thiazolidinedione-metformin treatment in diabetic participants: $* p<0.05, * * p<0.01$ and $* * * p<0.001$. Unless indicated otherwise, differences between treatment and pre-treatment values were not significant. $\dagger p<0.05$ for differences between mean values of

activation of all examined signalling factors required during insulin-stimulated glucose transport, i.e. IR, IRS-1/PI3K, aPKC and PKB $\beta / A k t 2$ in skeletal muscles of type 2 diabetic patients. As discussed, comparably large and widespread improvements in activation of these signalling factors were not evident when thiazolidinedione or metformin was used alone and clamp studies employed maximal insulin stimulation $[2,10]$. However, the question of whether thiazolidinedione or metformin treatment alone can comparably improve submaximal activation has not been studied.

The improvements in muscle aPKC activation with maximal insulin stimulation that were observed here following short-term 5- to 6-week combined thiazolidinedione-metformin treatment are similar to those seen with
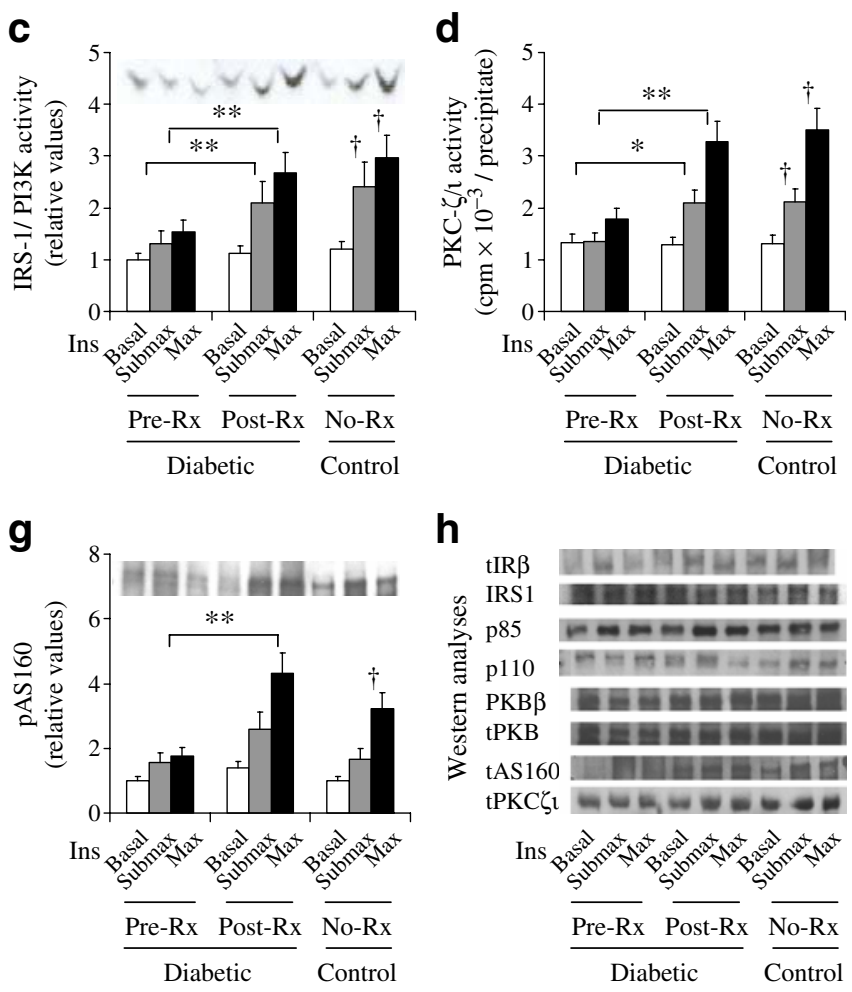

control and untreated diabetic participants. Insert (c) shows representative autoradiogram of $\mathrm{PI} 3 \mathrm{~K}$ reaction product, $\mathrm{PI} 3-\mathrm{PO}_{4}$. Inserts $(\mathbf{b}, \mathbf{f}$, g) show representative immunoblots of phosphorylated proteins in western blot analyses. h Western blot analyses of: total insulin receptor $\beta$-subunit (tIR $\beta$ ); IRS1; p85 subunit of PI3K (p85); p110 subunit of PI3K (p110); PKB $\beta$; total $\mathrm{PKB} \alpha / \beta$ (tPKB); total AS160 (tAS160); and total PKC zeta plus iota (tPKC- $/ / \mathrm{l})$. Note that: (1) samples within immunoblots routinely contained (or were prepared from) equal amounts of lysate protein; and (2) except for aPKC, which is diminished in muscles of type 2 diabetic participants, no significant changes were seen in levels of indicated signalling proteins in muscles of diabetic vs control participants or in diabetic muscles after vs before treatment. Accordingly, it may be inferred that the levels of phosphorylated proteins in immunoblots reflected alterations to the phosphorylation status of a given amount of the signalling protein, rather than a change in the amount of signalling protein

long-term (1 year) metformin treatment [10], but greater than those seen following comparable short-term treatment with either thiazolidinedione [2] or metformin alone [10]. Moreover, neither short-term nor long-term metformin treatment improved activation of IRS-1/PI3K or PKB/Akt $[9,10]$. Accordingly, the observed increases in activation of signalling factors following combined thiazolidinedionemetformin treatment reflects at least an additive, or more probably, synergistic effects of these agents.

The fact that combined thiazolidinedione-metformin therapy improved aPKC activation in diabetic muscle to levels of enzyme-specific activity observed in normal persons does not imply that insulin effects mediated through aPKC are fully normalised. Such thiazolidinedione-metformin therapy did not increase levels of muscle 
aPKC, and diminished amounts of total activated aPKC, as seen in type 2 diabetic muscle [2, 3], may limit glucose transport in intact muscle. On the other hand, as IRS-1 and $\mathrm{PKB} \beta / \mathrm{Akt} 2$ levels are not diminished in diabetic muscle [2, $4,9,10$, present results], the activation of IRS-1/PI3K and $\mathrm{PKB} \beta / \mathrm{Akt} 2$ was apparently largely restored by thiazolidinedione-metformin therapy and may not have contributed to the residual defect in glucose disposal following thiazolidinedione-metformin therapy.

It should be emphasised that the changes observed here in diabetic muscle following thiazolidinedione-metformin treatment probably reflect primary alterations in adipose and liver tissues, in which both medications are known to induce a number of effects that may impact favourably on insulin signalling in muscle. In this regard, the widespread improvements in all examined signalling factors may largely reflect the improvement in IR activation that was observed in the present study.

Finally, since hyperinsulinaemia can provoke increases in hepatic lipid synthesis [11] and therefore possibly abet the development or progression of atherosclerosis in type 2 diabetes, it was interesting to find that serum insulin levels diminished significantly following thiazolidinedione-metformin therapy. Salutary downward trends in serum glucose, triacylglycerol, total cholesterol and LDL-cholesterol were also observed, but an improvement in HDLcholesterol was not apparent in our short-term study. Accordingly, it will be of interest to observe alterations in these and other metabolic variables and clinical outcomes in long-term studies of thiazolidinedione-metformin therapy. In the meantime, the remarkable improvements in insulin signalling mechanisms in diabetic muscle and in metabolic variables that we observed following short-term combined thiazolidinedione-metformin treatment attest to its usefulness in treating type 2 diabetes, particularly in early phases of the disease.

Acknowledgements This work was supported by funds from the Department of Veterans Affairs Merit Review Program and National Institutes of Health Research Grant 2RO1-DK-38079.
Duality of interest The authors declare that there is no duality of interest associated with this manuscript.

\section{References}

1. Goodyear LJ, Giorgino F, Sherman LA, Smith RJ, Dohm GL (1995) Insulin receptor phosphorylation, IRS-1 phosphorylation, and phosphatidylinositol 3-kinase activity are decreased in intact skeletal muscle from obese subjects. J Clin Invest 95:2195-2204

2. Beeson M, Sajan MP, Dizon M et al (2003) Activation of protein kinase $\mathrm{C}-\zeta / \lambda / \iota$ by insulin and phosphatidylinositol-3,4,5-( $\left(\mathrm{PO}_{4}\right)_{3}$ is defective in muscle in type 2 diabetes and impaired glucose tolerance: amelioration by rosiglitazone and exercise. Diabetes 52:1926-1934

3. Kim Y-B, Kotani K, Ciaraldi TP, Henry RR, Kahn BB (2003) Insulin-stimulated $\mathrm{PKC}-\lambda / \zeta$ activity is reduced and PDK-1 activity is normal in muscle of insulin resistant humans. Diabetes 52:1935-1942

4. Casaubon L, Sajan MP, Rivas J et al (2006) Contrasting insulin dose-dependent defects in activation of atypical protein kinase $\mathrm{C}$ and protein kinase B/Akt in muscles of obese diabetic humans. Diabetologia 49:3000-3008

5. Kim Y-B, Nikoulina SE, Ciaraldi TP, Henry RR, Kahn BB (1999) Normal insulin-dependent activation of Akt/protein kinase B, with diminished activation of phosphoinositide 3-kinase in muscle in type 2 diabetes. J Clin Invest 104:733-741

6. Brozinick JT, Roberts BR, Dohm DL (2003) Defective signaling through Akt-2 and -3 but not Akt-1 in insulin-resistant skeletal muscle. Diabetes 52:935-941

7. Krook A, Roth RA, Jiang XJ, Zierath JR, Wallberg-Henriksson H (1998) Insulin-stimulated Akt activity is reduced in skeletal muscle from NIDDM subjects. Diabetes 47:1281-1286

8. Karlsson HKR, Zierath J, Kane S, Krook A, Lienhard GE, Wallberg-Henriksson H (2005) Insulin-stimulated phosphorylation of the Akt substrate AS160 is impaired in skeletal muscle of type 2 diabetic subjects. Diabetes 54:1692-1697

9. Kim Y-B, Ciaraldi TP, Kong A et al (2002) Troglitizone, but not metformin, restores insulin-stimulated phosphoinositide 3-kinase activity and increases $\mathrm{p} 110 \beta$ protein levels in skeletal muscle of type 2 diabetic humans. Diabetes 51:443-448

10. Luna V, Casauban L, Sajan MP et al (2006) Metformin improves atypical protein kinase $\mathrm{C}$ activation by insulin and phosphatidylinositol-3,4,5-( $\left.\mathrm{PO}_{4}\right)_{3}$ in muscle of diabetic subjects. Diabetologia $49: 375-382$

11. Farese R, Sajan MP, Yang H et al (2007) Muscle-specific knockout of PKC-lambda impairs glucose transport and induces metabolic and diabetic syndromes. J Clin Invest 117:2289-2301 